\title{
Incorporation of a SMES Coil Into a Superconducting LVdc Transmission System
}

\author{
B. K. Johnson
}

EE Department, University of Idaho, Moscow, Idaho 83844-1023

\author{
R. H. Lasseter and F. L. Alvarado \\ ECE Department, University of Wisconsin-Madison, Madison, Wisconsin 53706
}

\begin{abstract}
The performance of a superconducting low voltage direct current ( $\mathrm{LVdc}$ ) transmission system can be significantly enhanced through the addition of a superconducting magnetic energy storage (SMES) coil. The power conversion equipment necessary for connecting a SMES coil to a dc system is much simpler and easier to control than the interface needed to connect a SMES coil to an ac system. There is also added flexibility if the LVdc system is mesh connected. The LVdc system already has the power conditioning necessary for connection to the ac load and supply systems. The SMES coil can be connected to the LVdc mesh either through a dedicated dc-dc converter or it can be added directly into the mesh and controlled using the converters already present on the mesh. The rectifier voltage regulation schemes control the charging and discharging of the coil. If one of the rectifiers is supplied by a unit-connected generator, a simpler rectifier scheme can be used, and the generator field excitation control can be used to control the SMES coil. The SMES coil could then be used both to level generator loading and provide added reliability in case of disturbances on the ac supply system.
\end{abstract}

\section{INTRODUCTION}

The discovery of high temperature superconductivity [1] has sparked a great deal of interest in its application to the power area. One such application, low voltage power transmission, could have a significant impact on the layout of power grids in the future. A superconducting power system would operate at optimum generator voltages, resulting in a single voltage level from generation to distribution subsystems. There would no longer be a need to step up to high voltage levels for long distance transmission since $I^{2} R$ losses have been eliminated from the lines. So low voltage operation eliminates the need for high voltage insulation and large transformers [2]. Implementing such a system using direct current transmission eliminates losses resulting from eddy currents in the copper or aluminum matrix surrounding superconductor [3], [4], although there is a penalty from converter losses. However, this is offset by the enhanced ability to control system operation. Such a system is referred to as a low voltage direct current ( $\mathrm{LVdc}$ ) transmission system.

The performance of a superconducting LVdc transmission system can be significantly enhanced through the addition of a superconducting magnetic energy storage (SMES) coil. Possible benefits include load leveling, avoiding operation of high cost generation, and helping sensitive loads ride through disturbances. The power conversion equipment necessary for connecting a SMES coil to a de system

Manuscript Received August 26, 1996.

This work was a part of a project on High Temperature Superconducting DC Networks funded by NSF grant\#8818339 and EPRI Project RP7911-12, is much simpler and easier to control than the interface needed to connect a SMES coil to an ac system [5], [6], [7], [8]. There is also added flexibility if the LVdc system is mesh connected since there are now parallel transmission paths. The LVdc system already has the power conditioning necessary for connection to the ac load and supply systems. The SMES coil can be connected to the LVdc system either through a dedicated dc-dc converter or it can be added directly into the mesh and controlled using the converters already present on the mesh. The latter approach is presented in this paper. The rectifier voltage regulation schemes control the charging and discharging of the coil as part of the voltage droop control scheme [9], with minor modifications required for the rectifier supplying the SMES coil. If one of the rectifiers is supplied by a unit-connected generator, an uncontrolled rectifier scheme can be used, and the generator field excitation control can be used to control the voltage across the SMES coil. The SMES coil could then be used both to level generator loading and provide added reliability in case of disturbances on the ac supply system.

This paper will discuss modifications required to add a SMES coil into a superconducting LVdc network, beginning with a review of the $L V d c$ transmission system and the voltage droop scheme. Modifications to the control scheme will be discussed, followed by results of computer simulation of the resulting system.

\section{LVDC Transmission Systems}

Implementing an ac transmission system with high temperature superconductors results in hysteretic losses in the superconductor and eddy current losses in the copper or aluminum matrix surrounding the superconducting material. Current levels may then be restricted to reduce losses, and the system voltage level will need to increase to transfer the same amount of power. Long ac transmission lines and cables require reactive compensation (shunt or series connected capacitors and inductors) to maintain power transfer capability and provide adequate voltage regulation. Superconducting cables used for ac transmission would have similar compensation requirements.

A low voltage dc ( $\mathrm{LVdc}$ ) superconducting transmission system eliminates the problem of ac losses, but introduces other system issues. A mesh-connected dc system improves reliability by providing redundant transmission paths. Difficulties with a superconducting, mesh-connected LVdc system relate primarily to the distribution of steady state and transient currents in the dc mesh [10], system protection, and power conversion issues. The $\mathrm{dc} / \mathrm{ac}$ conversion process 


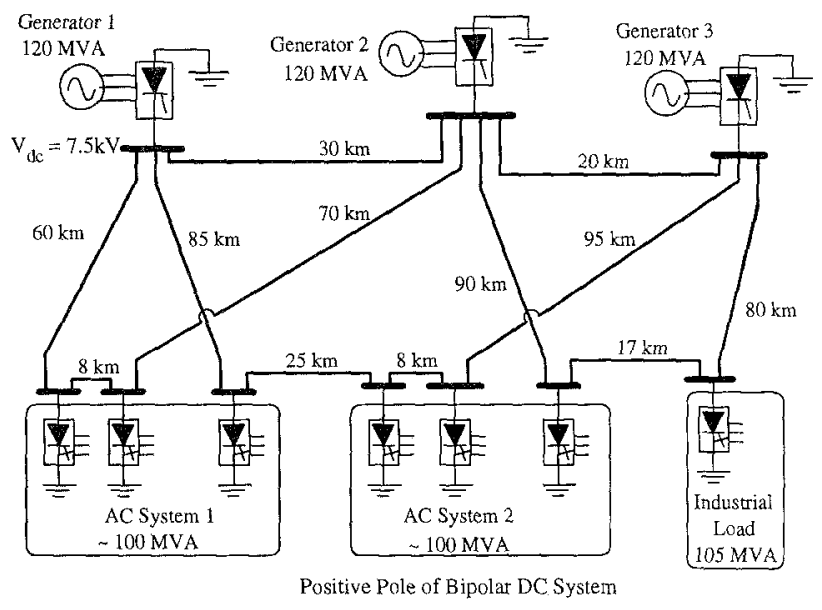

Fig. 1. Ten Terminal LVdc Study System

injects harmonic currents onto the dc system that result in harmonic losses.

The dc system is controlled so the ac system sees the dc mesh as an asynchronous system capable of delivering power from generation sites to distribution substations without transmission losses. Control of the dc system takes advantage of superconducting cable properties. All nodes on the dc system reach the same steady-state voltages due to the lossless transmission lines [10]. The dc voltage level is maintained by voltage control at one or more of the rectifier terminals. Thus, voltage on the dc mesh is a systemwide quantity in the same fashion as frequency in conventional ac systems.

The evolution of dc systems has been hampered by the difficulties associated with multi-converter configurations, where classical control schemes require mode switching [11], [12], [13], [14]. As a result initial application of su perconducting low voltage $\mathrm{dc}(\mathrm{LVdc})$ systems will probably begin with point-to-point dc systems. These systems can be expanded by adding parallel taps for additional rectifier and inverter terminals. The low voltage level allows for simple modular converters. The voltage level can be on the order of $7.5 \mathrm{kV}$, within the voltage ratings of high power thyristors, eliminating the need for the series connection of devices within converters. Simple six-pulse modules could be connected in parallel to achieve a desired current rating. This suggests a system with a large number of "off the shelf" mass produced converter modules. A typical LVdc transmission system could consist of numerous rectifiers feeding hundreds of inverter terminals. The LVdc system could continue to grow through the addition of terminals and lines, forming a dc mesh for increased transmission reliability. A possible configuration is shown in Fig. 1. For more details on the concept of superconducting meshed systems, refer to [3], [4].

\section{DC Voltage Droop Control}

A distributed voltage regulation scheme must maintain consistent sharing of current between the rectifiers. A useful analogy is the use of frequency droop to provide natural regulation characteristics for all generators in an ac

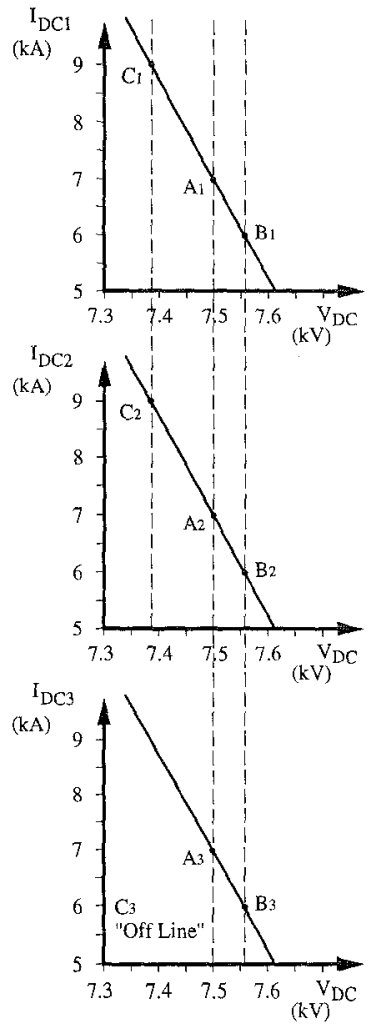

Fig. 2. Example of the dc Droop Scheme for the System with Three Rectifiers

system. A sloping power versus frequency natural regulation characteristic is used for each generator to regulate the initial distribution of real power among generators. This scheme uses a change in frequency as a signal for the control system to meet changes in power demand. Natural regulation requires no communications, and it is followed by load-frequency control which refers to automatic means of regulation responsive to frequency, tie flows and other system variables [15]

A voltage droop scheme can be implemented for ordinary dc systems, but it is easier to implement for a superconducting system [9]. Each of the nodes on the dc system reaches the same steady-state voltage level since there will be no resistive voltage drops on the lines. Thus, it is possible to use the voltage on the dc system as a control signal. As the current drawn from one of the rectifiers is increased, the system voltage will decrease slightly, causing the currents supplied by the other rectifiers to also increase until the system reaches a new steady state, as shown in Fig. 2.

The analogy to generators is not perfect. The control of ac voltage provided by generators has no counterpart in the regulation of the $\mathrm{dc}$ mesh, since reactive power is not a valid concept for the dc network. Voltage replaces frequency as a system-wide signal, and there is no second quantity that needs regulation. 


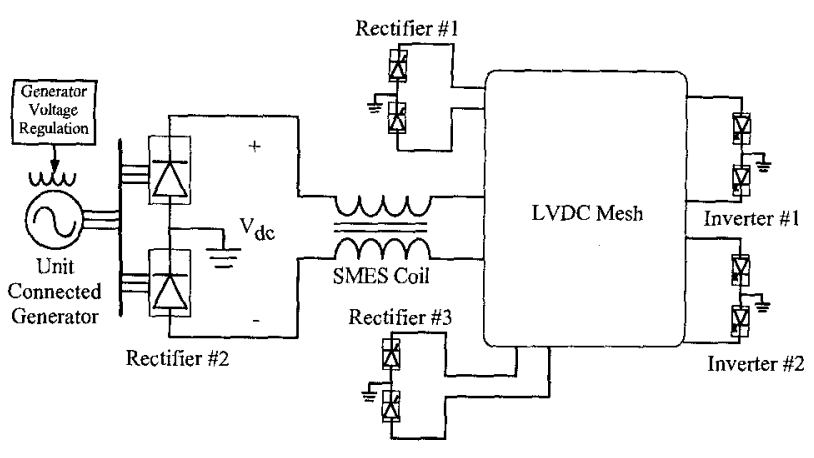

Fig. 3. Interfacing a SMES Coil with the LVdc Mesh

\section{InCORPoration of a SMES COIL}

The power conversion equipment necessary for connecting a SMES coil to a dc system is much simpler and easier to control than the interface needed to connect a SMES coil to an ac system [5], [6], [7], [8]. The SMES coil could then be used for load leveling on the transmission system. Previous studies have looked at the possibilities of adding a SMES coil to an LVdc system [10]. If done properly no extra converters are needed to add a SMES coil to an LVdc system, and few modifications in the controls are needed.

There are several options for adding a SMES coil to the $\mathrm{LVdc}$ system. One option is to interface the coil through a dedicated $\mathrm{dc}-\mathrm{dc}$ converter. This has the disadvantage of requiring an additional converter. A better option is to connect the SMES coil in series with one of the rectifiers. The other end of the coil would then be connected to the dc mesh. The current path would be completed through the superconducting network. The rectifier would control the voltage on one side of the coil, while the system voltage droop scheme would regulate the voltage on the other side of the coil. The rectifier voltage control scheme is used to regulate the voltage across the coil and therefore controls charging/discharging of the coil. This can be a fairly slow control loop. The basic configuration for such a system is shown in Fig. 3.

The SMES coil is easiest to control if there is a stiff voltage source on each side of the coil. If the rectifier is fed by a unit-connected generator (one that supplies no local ac load), so can be operated as a stiff dc voltage source, with the generator voltage regulator maintaining the voltage on the rectifier side of the coil. In this case the rectifier feeding the coil can also be implemented using a diode bridge [16]. This arrangement does not suffer from some of major problems that limit the usefulness of diode bridges for HVDC transmission since the coil will limit the rate of rise of the rectifier current during $d c$ faults and the coil does not require fast voltage magnitude control at the rectifier [4], [10]. Therefore the slower voltage control circuits in the generator and the inability to create a bypass pair will not hurt system performance. The other rectifier terminals on the mesh will regulate the voltage on the mesh side of the SMES coil.

The coil is charged by either decreasing the mesh volta.ge level or by increasing the voltage on the rectifier side of
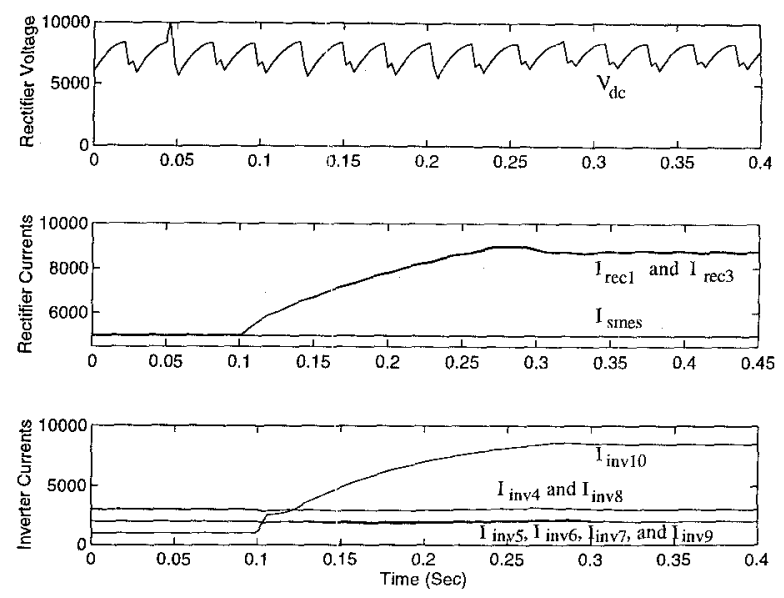

Fig. 4. EMTP Simulation with Load Current Increased by $33 \%$

the coil. Both of these result in a voltage difference across the coil that will increase its current, and thus the energy stored in it. Increasing the mesh voltage will increase the energy drawn off of the coil by the mesh until the coil current begins to drop. The rectifier supplying the SMES coil does not participate in the voltage droop control scheme, since the coil effectively isolates it from the system.

\section{Computer Simulation Results}

A SMES coil was added to the system shown in Fig. 1 between the rectifier connected to generator 2 and the dc mesh. A coil with an inductance of $10 \mathrm{H}$ was added. The resulting system was simulated using the Electromagnetic Transients Program (EMTP). Detailed models for the converters were utilized that included all of the converter controls as well as the power electronic devices.

The system starts out with each of the rectifiers supplying $5000 \mathrm{~A}$ to the LVdc mesh at a dc voltage of $7500 \mathrm{~V}$ (15 $\mathrm{kV}$ line-to-line in the bipolar system). The inverter currents currents range from $1000 \mathrm{~A}$ to $3000 \mathrm{~A}$ initially. The SMES coil is passing current through to the loads at the same time it is also storing energy in its magnetic field. Fig. 3 starts out in this initial state.

The load current at inverter 10 is then increased by 5000 A (representing a $33 \%$ increase in total load on the system). The simulation results show that the other two rectifiers increase the current they supply to the system while the current through the SMES coil remains unchanged.

The first plot in Fig. 3 shows the voltage on the rectifier side of the coil. Notice that the voltage is kept constant during the simulation. The second plot shows the rectifier currents, with the currents through rectifiers 1 and 3 following the change in load, while the current through the SMES coil does not show a noticeable change. The third plot shows the inverter currents.

The next case shows the response when the generator supplying rectifier 2 is shut down. The results are shown in Fig. 4. The loss of the generator brings the voltage on the rectifier side of the coil to zero and the coil discharges slowly into the system. 

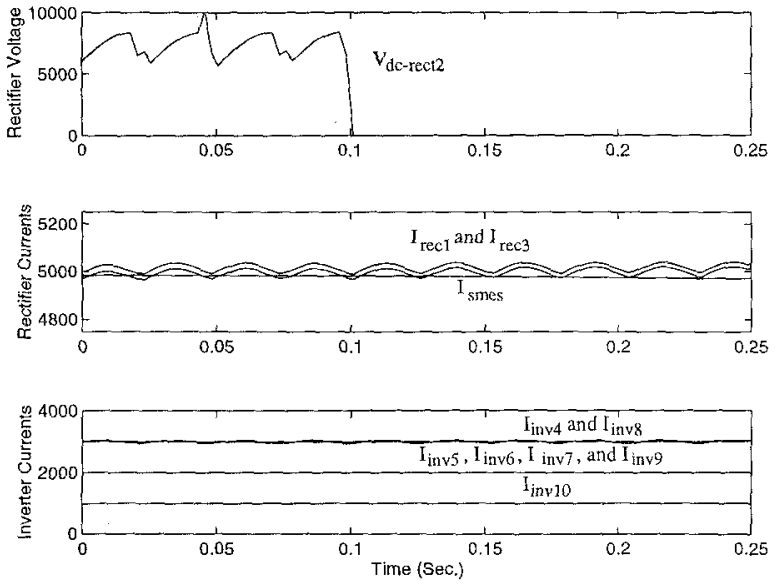

Fig. 5. EMTP Simulation with the Loss of the Generator 2

The first plot in Fig. 4 shows the voltage on the rectifier side of the coil. Notice that the voltage goes to zero. The second plot shows the rectifier currents, with the currents through rectifiers 1 and 3 tracking together. Notice that the current through the SMES coil is starting to drop and the currents through the other two rectifiers are beginning to increase to compensate. The third plot shows that the inverter currents are unaffected.

\section{VT. CONCLUSION}

An efficient scheme for adding a SMES coil into a superconducting LVdc transmission system was presented. The SMES coil is added in series with one of the rectifiers, allowing the voltage control scheme for that rectifier to regulate the charging/discharging of the coil in response to changes in the system voltage, which is controlled using a voltage droop scheme. The basics behind the LVdc system and the voltage droop scheme were presented, followed by a description of the method for incorporating the SMES coil into the system. This was followed by EMTP simulation results showing operation of the system with the SMES coil present.

\section{REFERENCES}

[1] J.G. Bednorz and K.A. Müller, Possible High $T_{c}$ Superconductivity in the Ba-La-C $u_{-}$O System. Zeits. Physik, B64, 189, 1986.

[2] R.F. Giese, T.P. Sheahan, A.M. Wolsky, D.K. Sharma, "HighTemperature Superconductors: Their Potential For Utility Applications," IEEE Transactions on Energy Conversion. Vol. 7, No. 3, pp. 589-597, September 1992.

[3] B.K. Johnson, R.H. Lasseter, F.L. Alvarado, D.M. Divan, H. Singh, M.C. Chandorkar, and R. Adapa, "High-Temperature Superconducting dc Networks," IEEE Transactions on Applied Superconductivity. Vol. 4, No. 3, pp. 115-120, September 1994.

[4] R.H. Lasseter, F.L. Alvarado, D.M. Divan, B.K. Johnson, H. Singh, and M.C. Chandorkar, Superconducting LVDC Networks. Palo Alto, California, Electric Power Research Institute, EPRI TR-103636, April 1994.

[5] H. Okada, T. Ezaki, K. Ogawa, H. Koba, M. Takeo, K. Funaki, S. Sato, F. Irie, J. Chikaba, K. Terazono, M. Takamatsu, N. Kawakami, and M. Hirano, "Experimental Studies of SMES System with DC Intertie for Power Line Stabilization," 1988 IEEE Power Electronic Specialists Conference. pp. 326-333, paper No. II D-5, April 1988.

[6] R.H. Lasseter and S.G. Jalali, "Power Conditioning Systems for Superconductive Magnetic Energy Storage," IEEE Transactions on Energy Conversion. Vol. 6, No. 3, pp. 381-387, September 1991.

[7] R.H. Lasseter and S.G. Jalali, "Dynamic Response of Power Conditioning Systems for Superconductive Magnetic Energy Storage," IEEE Transactions on Energy Conversion. Vol. 6, No. 3, pp. 388-393, September 1991.

[8] K.S. Tam and P. Kuman, "Application of Superconducting Magnetic Energy in an Asynchronous Link Between Power Systems," IEEE Transactions on Energy Conversion. Vol. 5, No. 3, pp. 436-444, September 1990.

[9] B.K. Johnson, R.H. Lasseter, F.L. Alvarado, and R. Adapa, "Expandable Multiterminal dc Systems Based on Voltage Droop," IEEE Transactions on Power Delivery. Vol, 8, No, 4, pp. 19261932, Nov. 1994.

[10] B.K. Johnson, R.H. Lasseter and R. Adapa, "Power Control Applications on a Superconducting LVDC Mesh," IEEE Transactions on Power Delivery. Vol. 6, No. 3, pp. 1282-1288, July 1991.

[11] J. Reeve, "Multiterminal HVdc Power Systems," IEEE Trans. on Power Apparatus and Systems. Vol, 99, pp. 729-737, March/April 1980.

[12] R. Foerst, G. Heyner, K.W. Kanngiesser, and H. Waldmann, "Multiterminal Operation of HVdc Converter Stations," IEEE Trans. on Power Apparatus and Systems. Vol. 88, pp. 1042-1052, July 1969.

[13] R. Jötten, J.P. Bowles, G. Liss, C.J.B. Martin, and E. Rumpf "Control in HVdc Systems, The State of the Art, Part II: Multiterminal Systems," CIGRE 14-07 28th Session Paris, France, 1980.

[14] R.H. Lasseter, K.H. Krüeger, and D. Povh, "Control of Multiterminal de Systems," MONTECH '86, Montreal, Canada, No. THO-154-5, pp. 120-125, 1986.

[15] N. Cohn, Control of Generation and Power Flow on Interconnected Power Systems. New York: Wiley, 1961.

[16] J. P. Bowles, "Multiterminal HVdc Transmission Systems Incorporating Diode Rectifier Stations," IEEE Transactions on Power Apparatus and Systems. Vol. PAS-100, No. 4, pp. 16741678, April 1981 